\title{
Bleeding Management of Uterine Conization Using a Pasteurized FVIII/VWF Concentrate in a Woman Affected by Type 2A von Willebrand Disease
}

To the editor,

This is the first reported case of conization of the uterine cervix performed in a patient affected by type $2 \mathrm{~A}$ von Willebrand disease (VWD). Hemostasis was successfully achieved with the simultaneous use of diathermic loop electrocautery and a pasteurized plasma-derived FVIII/VWF concentrate (Haemate P) with a high ristocetin cofactor activity of von Willebrand factor (VWF:RCo). Treatment schedule and postsurgery FVIII, VWF:RCo, and von Willebrand factor antigen (VWF:Ag) plasma levels are described.

Conization of the uterine cervix is a surgical technique that allows radical excision of potentially malignant but still limited lesions without disrupting both uterine anatomy and function. It can be performed using cold knife, but newer technologies such as diathermic loop electrocautery and laser excision are available. ${ }^{1}$ Cold knife conization remains the preferred technique as it provides adequate tissue samples for histological examination unlike laser or electrosurgical excision in which the coagulation effect disrupts the anatomy of lesions, thus modifying the future management of the malignancy. ${ }^{2}$

Regardless of the technique used, bleeding is the main complication of cervix conization. Other complications include infection, cervical stenosis, and cervical incompetence, which especially occurs during the excision of large cones. ${ }^{3}$ Bleeding can occur both perioperatively and as a late complication, mainly during the removal of necrotic eschar, which happens approximately 1 week after the intervention. The amount of blood loss is generally limited, but hemorrhage can be life-threatening ${ }^{4}$ and underlying congenital bleeding disorder has been reported in such cases. ${ }^{5}$ Comparison studies of the 3 methods dealt not only with efficacy and long-term outcome but also with bleeding complications, which have been shown to be significantly lower in women treated with diathermic loop conization. ${ }^{6}$

We report the outcome of uterine cervix conization performed in a woman affected by VWD, as no clinical observation has been reported on this procedure. The patient was a 30-year-old woman with type 2A VWD disease and a personal history of lifethreatening bleeding after surgery including delivery. She underwent a routine gynecological evaluation, which showed a cervical intraepithelial neoplasia (CIN2) without evidence of microinvasion. Excision was performed using the diathermic loop because of its proved hemostatic efficacy. A recent retrospective extensive survey regarding the use of Haemate $\mathrm{P}$ confirmed its effectiveness and safety when used for surgical prophylaxis in patients affected by any type of VWD. ${ }^{7}$

As suggested by Mannucci, ${ }^{8}$ a dose of Haemate P (50 FVIII:C IU/kg/day) was administrated 30 minutes prior to the intervention by bolus infusion. Intravenous tranexamic acid was started intraoperatively by continuous infusion at a rate of $15 \mathrm{mg} / \mathrm{kg}$. Treatment was able to control bleeding during the surgical procedure, and the 12-hour postinfusion VWF:Ag plasma levels were higher than $50 \%$ of normal levels, whereas FVIII:C and VWF:RCo plasma levels were less than $50 \%$ of normal levels but still markedly higher than the patient's baseline (Figure 1). The patient received the same daily dose of Haemate $P$ for the next 3 days without discontinuing tranexamic acid, resulting in complete stoppage of bleeding. The same schedule, with the exception of oral administration of tranexamic acid, was successfully used 1 week after discharge when the necrotic eschar was removed from the uterine cervix. 


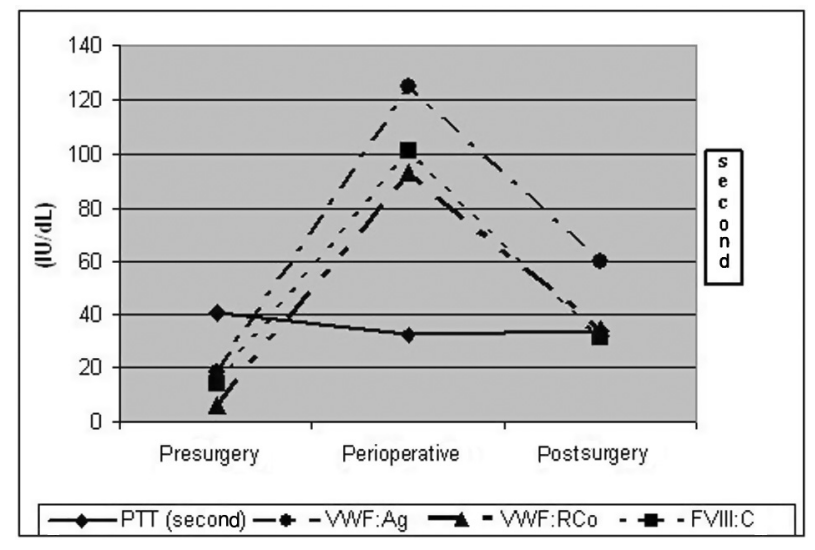

Figure 1. Coagulation parameters (checked before and after 1 and 12 hours after the infusion of 2000 IU plasma).

In conclusion, diathermic loop electrocautery together with an FVIII/VWF concentrate prevented bleeding in a conservative surgical procedure performed in a patient at high risk of hemorrhage because of a congenital bleeding disorder. Our experience encourages the use of diathermic loop conization, because of its hemostatic superiority over the cold knife method, when excision of a malignant lesion not suspected to cross the epithelial environment is needed in patients affected by VWD.

Mario Lapecorella, MD

Mariasanta Napoletano, MD

Guglielmo Mariani, MD

Haemophilia and Thrombosis Centre

University of L'Aquila, Italy

Giulio Mascaretti, MD

Emanuele Colageo, MD

Obstetrics and Gynaecology Unit

University of L'Aquila, Italy

\section{References}

1. Cirisano FD. Management of pre-invasive disease of the cervix. Semin Surg Oncol. 1999;16:222-227.

2. Oyesanya OA, Amerasinghe CN, Manning EA. Outpatient excisional management of cervical intraepithelial neoplasia. A prospective, randomized comparison between loop diathermy excision and laser excisional conization. Am J Obstet Gynecol. 1993;168:485-488.

3. Mathevet P, Dargent D, Roy M, Beau G. A randomized prospective study comparing three techniques of conization: cold knife, laser, and LEEP. Gynecol Oncol. 1994;54:175-179.

4. Kurata H, Aoki Y, Tanaka K. Delayed, massive bleeding as an unusual complication of laser conization. A case report. J Reprod Med. 2003;48:659-660.

5. Kim SH, Srinivas SK, Rubin SC, Freedman LJ, Gray HJ. Delayed hemorrhage after cervical conization unmasking severe factor XI deficiency. Obstet Gynecol. 2004;104:1189-1192.

6. Brun JL, Youbi A, Hocke C. Complications, sequelae and outcome of cervical conizations: evaluation of three surgical techniques. J Gynecol Obstet Biol Reprod (Paris). 2002;31:558-564

7. Federici AB, Castaman G, Franchini M, et al. Clinical use of Haemate P in inherited von Willebrand's disease: a cohort study on 100 Italian patients. Haematologica. 2007;92:944-951.

8. Mannucci PM. Treatment of von Willebrand's disease. N Engl J Med. 2004;351:683-694. 